Brian B. Schmidt

\title{
The Materiality of Power
}

\section{Explorations in the Social History of Ancient Israelite Magic}

[Die Materialität der Macht. Untersuchungen zur Sozialgeschichte der Magie im antiken Israel.]

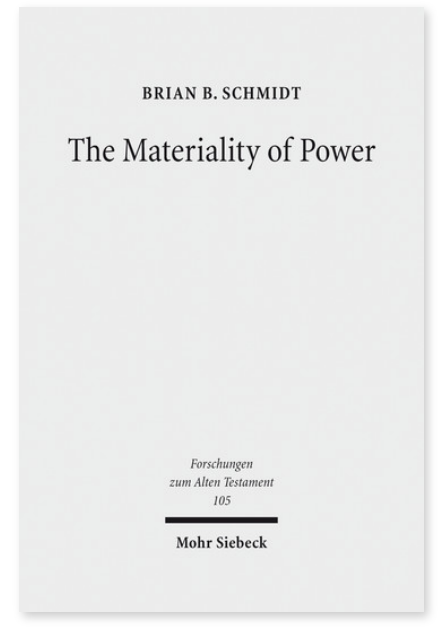

2016. XV, 258 Seiten. FAT 105

ISBN 978-3-16-154709-6

DOI 10.1628/978-3-16-154709-6

eBook PDF 114,00€

ISBN 978-3-16-153302-0

Leinen $114,00 €$
Veröffentlicht auf Englisch.

Brian B. Schmidt präsentiert fünf Fallstudien, in denen architektonische Räume, Artefakte, Inschriften und biblische Handschriften die Existenz eines kraftvollen daimonischen Reichs im späten vorexilischen Israel bestätigen, zusammen mit einem rudimentären Pandämonium, das spätere dämonologische Konstrukte ahnen ließ. Die materiellen und die epigraphischen Daten aus Kuntillet Ajrud, Ketef Hinnom und Khirbet el-Qom, in Verbindung mit den Textzeugnissen aus Dtn 32 und 1 Sam 28, zeigen, dass Mitglieder dieses Pandämoniums verheerenden Schaden unter den Lebenden und den Toten anrichteten. Die gleichen Daten belegen, dass es auch ein ausgleichendes, apotropäisches Reich gab - ein Reich, über das JHWH und seine Aschera, dargestellt als die zwei international anerkannten Schutzgottheiten Bes und Beset, gemeinsam herrschten und in welchem Ascherah als JHWHs Mittlerin diente. Darüber hinaus vermitteln verschiedene andere materielle Medien wie Amulette und gravierte Segenssprüche, welche entworfen wurden, um die apotropäische Macht auszudrücken, das Entgegenwirken dieses Reichs.

Brian B. Schmidt B.S., Th.M., D.Phil. (Oxon.); completed graduate studies at The Hebrew University of Jerusalem and The University of North Carolina at Chapel Hill; currently Professor of Biblical Studies and Ancient West Asian Cultures in the Department of Middle East Studies at The University of Michigan, Ann Arbor.

\section{Jetzt bestellen:}

https://mohrsiebeck.com/buch/the-materiality-of-power-9783161547096?no_cache=1

order@mohrsiebeck.com

Telefon: +49 (0)7071-923-17

Telefax: $+49(0) 7071-51104$ 